\title{
THE
}

2012

\section{Vegetation and Invertebrate Community Response to Eastern Hemlock Decline in Southern New England}

\author{
Laura L. Ingwell \\ University of Rhode Island \\ Mailea Miller-Pierce \\ University of Rhode Island \\ R. Talbot Trotter III \\ Evan L. Preisser \\ University of California - Davis, preisser@uri.edu
}

Follow this and additional works at: https://digitalcommons.uri.edu/bio_facpubs

Terms of Use

All rights reserved under copyright.

\section{Citation/Publisher Attribution}

Ingwell, L. L., Miller-Pierce, M., Trotter, R. T., III, \& Preisser, E. L. (2012). Vegetation and Invertebrate Community Response to Eastern Hemlock Decline in Southern New England. Northeastern Naturalist, 19(4), 541-558. doi: 10.1656/045.019.0402

Available at: https://doi.org/10.1656/045.019.0402

This Article is brought to you for free and open access by the Biological Sciences at DigitalCommons@URI. It has been accepted for inclusion in Biological Sciences Faculty Publications by an authorized administrator of DigitalCommons@URI.For more information, please contact digitalcommons-group@uri.edu. 


\section{Vegetation and Invertebrate Community Response to Eastern Hemlock Decline in Southern New England}

Author(s): Laura L. Ingwell, Mailea Miller-Pierce, R. Talbot Trotter III and Evan L. Preisser

Source: Northeastern Naturalist, 19(4):541-558.

Published By: Eagle Hill Institute

https://doi.org/10.1656/045.019.0402

URL: http://www.bioone.org/doi/full/10.1656/045.019.0402

BioOne (www.bioone.org) is a nonprofit, online aggregation of core research in the biological, ecological, and environmental sciences. BioOne provides a sustainable online platform for over 170 journals and books published by nonprofit societies, associations, museums, institutions, and presses.

Your use of this PDF, the BioOne Web site, and all posted and associated content indicates your acceptance of BioOne's Terms of Use, available at www.bioone.org/page/ terms of use.

Usage of BioOne content is strictly limited to personal, educational, and non-commercial use. Commercial inquiries or rights and permissions requests should be directed to the individual publisher as copyright holder. 


\title{
Vegetation and Invertebrate Community Response to Eastern Hemlock Decline in Southern New England
}

\author{
Laura L. Ingwell ${ }^{1,2, *}$, Mailea Miller-Pierce ${ }^{1,3}$, R. Talbot Trotter III ${ }^{4,5}$, \\ and Evan L. Preisser ${ }^{1}$
}

\begin{abstract}
The introduction of Adelges tsugae (Hemlock Woolly Adelgid [HWA]) to the eastern United States has had a devastating impact on Tsuga canadensis (Eastern Hemlock). Although much research has been done to assess HWA impacts on ecosystem processes and vegetation structure, few researchers have examined community-level changes in highly infested forest stands. Here we assess the impact of Eastern Hemlock mortality on vegetation and invertebrate diversity and community structure by comparing low-impact (healthy) stands and stands heavily impacted by HWA. We sampled the vegetative and invertebrate diversity of 8 sites (4 low impact and 4 high impact) in the summer and fall of 2008. We found a shift in the understory plant community and the canopy and subcanopy arthropod communities. Herbaceous plant species richness was significantly higher at high-impact sites, with Betula lenta (Black Birch) being the most common woody species. Overall, forest invertebrate community diversity (measured using the Shannon-Weaver diversity index) was greater in high- versus low-impact sites. Of the 21 indicator species significantly associated with a given forest type, 14 and 7 species were associated with high- and low-impact forests, respectively. Variation in arthropod community structure was driven by above-ground differences; ground-level arthropod community composition did not differ between high- and low-impact sites. These results demonstrate some of the biodiversity impacts that can result from the invasion of an exotic insect into forested systems.
\end{abstract}

\section{Introduction}

Tsuga canadensis Carrière (Eastern Hemlock) is a long-lived and shadetolerant tree that is the dominant conifer species in many forest ecosystems in the eastern United States. Eastern Hemlock has been described as a "foundation species" whose presence defines an ecosystem and provides the conditions necessary for many species to exist (Ellison et al. 2005a). Mature hemlocks add to structural diversity both within stands and across the landscape, providing habitat for a range of terrestrial species while shading the headwater streams in which many aquatic species thrive (DeGraaf et al. 1992, Snyder et al. 2002, Tingley et al. 2002).

Eastern Hemlock is currently threatened in the southern and central part of its geographic range by the invasive Adelges tsugae Annand (Hemlock Woolly

\footnotetext{
${ }^{1}$ Department of Biological Sciences, University of Rhode Island, Kingston, RI 02881. ${ }^{2}$ Department of Entomology, University of Idaho, Moscow, ID 83844. ${ }^{3}$ School of Biological Sciences, Washington State University, Vancouver, WA 98686. ${ }^{4}$ USDA Forest Service, Northeastern Research Station, Hamden, CT 06514. ${ }^{5}$ Yale School of Forestry and Environmental Studies, New Haven, CT 06511. *Corresponding author - laura.ingwell@gmail.com.
} 
Adelgid [HWA]). HWA is a sap-sucking hemipteran native to Japan, which was first documented in the USA in Virginia in the early 1950s (Havill et al. 2006, Orwig and Foster 1998). Since its discovery, it has spread rapidly across the geographic range of Eastern Hemlock, and currently infests stands from northern Georgia to southern Maine (McClure 1987, Orwig and Foster 1998, USDA Forest Service 2010). HWA can kill mature hemlocks in as few as four years (but see Ingwell and Preisser 2011), and HWA-induced hemlock mortality has been documented in all but the most recently colonized portions of the invaded range (McClure 1991).

Changes in local and regional biodiversity driven by biological invasions are a serious conservation concern and management challenge. Loss of Eastern Hemlock may lead to regional homogenization of forest structure and declines in biodiversity (Ellison et al. 2005b, Tingley et al. 2002). Models of forest dynamics in the central part of the Appalachians, for example, predict that within 20 years of HWA presence, forest stand structure can be completely altered from hemlock-dominated stands to a dense deciduous hardwood community (Spaulding and Rieske 2010). Much work has been done on HWA's role in changing ecosystem processes (Kizlinski et al. 2002, Orwig et al. 2002, Spaulding and Rieske 2010, Stadler et al. 2005), and we are beginning to understand the effect of hemlock loss on hemlock-associated organisms. Ellison et al. (2005b) documented regional reductions in ant species richness in forests with high levels of hemlock mortality. Tingley et al. (2002) found that hemlock mortality was correlated with sharp reductions in the densities of several bird species. They also found that hemlock mortality reduced breeding population densities and/or led to the local extirpation of two hemlock obligates, Dendroica virens Gmelin (Black-throated Green Warbler) and Empidonax virescens Vieillot (Acadia Flycatcher). In addition, Snyder et al. (2002) examined aquatic invertebrate diversity by comparing streams in hemlock stands to those in hardwood stands. They found 11 taxa that were strongly associated with hemlock forests, 3 of which were found exclusively in hemlock-shaded streams.

In light of the essential role played by terrestrial invertebrates in forest food webs, research assessing the effects of HWA on invertebrate diversity is important for addressing conservation issues and future restoration efforts (Mahan et al. 2004). Despite this need for information, there have been relatively few studies assessing the broader invertebrate communities that are associated with Eastern Hemlock forests. Falcone and DeWald (2010) examined invertebrate communities in imidacloprid-treated and untreated stands of HWA-infested Eastern Hemlock in the eastern region of Great Smoky Mountain National Park (GSMNP) in North Carolina and Tennessee and found a decrease only in Lepidoptera larvae in the imidacloprid-treated sites. Dilling et al. (2007) examined the structure of insect guilds associated with immature and mature hemlock forests in GSMNP in Tennessee. They found Eastern Hemlock forests were dominated by transient $(33.5 \%)$, scavenger $(25.5 \%)$, and predator $(22.2 \%)$ guilds. While both 
of these studies were based in the southern-most portion of the Eastern Hemlock range, Rohr et al. (2009) compared insect species and functional groups associated with Eastern Hemlock and their expected replacement (mixed-hardwood forests) in the mid-Atlantic region of the Appalachian Mountains in Virginia. They identified 23 taxa that were significant indicators of hardwood forests and 7 taxa that were indicators of hemlocks. They predicted that a net increase in arthropod abundance and family-level diversity would occur as hardwoods replace hemlock stands in the Appalachians.

Here, we extend the geographic range of these studies and more directly measure the impact of HWA by evaluating differences in the community composition in heavily and lightly affected hemlock stands in New England. Specifically, we use an approach similar to that of Rohr et al. (2009), to investigate the immediate response of invertebrate and vegetative communities to HWA-associated hemlock mortality. While previous studies have focused on hemlock stands in the southern and central portions of the HWA-invaded range, ours is the first to examine invertebrate and vegetative community responses in New England, where the population dynamics of the adelgid and its impacts are more heterogeneous both spatially (Preisser et al. 2008) and temporally (Paradis et al. 2008), as a result of the proximity of populations to their ecological limits. The patchy nature of adelgid impacts in New England (Preisser et al. 2008) provides the opportunity to directly compare HWA-devastated Eastern Hemlock stands to healthy hemlock forests in the same region. We used previously compiled datasets (from Orwig and Foster 1998, Preisser et al. 2008) to identify stands with low and high levels of HWA infestation and hemlock mortality while minimizing differences in terrain, such as elevation, soil type, and secondary vegetation (Young et al. 2002). Our objective was to describe vegetation and invertebrate communities associated with Eastern Hemlock forests and changes in these communities resulting from HWA-associated hemlock decline.

\section{Field-Site Description and Methods}

\section{Study design and site selection}

We compared vegetation and terrestrial invertebrate diversity and community structure in heavily HWA-affected stands with nearby $(\approx 50 \mathrm{~km})$ stands that have suffered relatively little HWA-related damage. Because HWA has invaded New England from the south and moved northward, we can use a "space-for-time substitution" experimental design (Cowles 1899) that uses the existing geographic gradient of HWA infestation as a proxy for a temporal gradient. This design is essential because changes within an individual forest stand may take years to manifest. We sampled the vegetation and invertebrate communities in 8 hemlock stands, choosing 4 stands in southern Connecticut that show a great degree of HWA-induced mortality (high impact) and 4 stands in northern Connecticut that are healthy with low HWA infestation 
levels (low impact) (Preisser et al. 2008 provides stand-level HWA impacts). Sites were selected from a pre-existing dataset of 79 hemlock stands (surveyed in 1997/98, 2005, and 2007) located throughout Connecticut. Each stand has been extensively surveyed for a variety of ecosystem characteristics such as elevation, slope, aspect, terrain shape (concave or convex), solar illumination, and vegetation composition (Orwig and Foster 1998). These stands have also been repeatedly surveyed for HWA density, hemlock mortality, and overall stand health (Preisser et al. 2008, 2011). In order to strengthen our ability to perform between-site comparisons, we chose sites with similar terrain, hardwood co-dominants, and understory vegetation communities (Young et al. 2002). Our goal was to minimize regional variability in order to detect changes directly associated with HWA infestations. The sites we chose had similar slopes (low impact: $9.7 \pm 5.61 \%$; high impact: $21.3 \pm 7.38 \%$ ), stand areas (low impact: $44.6 \pm 9.48$ ha; high impact: $36.5 \pm 12.17$ ha), and humus depths (low impact: $4.21 \pm 0.59 \mathrm{~cm}$; high impact: $3.88 \pm 1.42 \mathrm{~cm}$ ). The lowand high-impact sites were also similar in deciduous tree size (low impact: $21.4 \pm 1.15 \mathrm{~cm} \mathrm{dbh}$; high impact: $23.7 \pm 1.92 \mathrm{~cm} \mathrm{dbh}$ ) and crown class (low impact: $2.4 \pm 0.11$; high impact: $2.6 \pm 0.09$; see Orwig and Foster 1998 for a detailed explanation of this variable). The high-impact study sites located in southern Connecticut had experienced 35-70\% stand losses of Eastern Hemlock in the mid-1990s due to HWA (see Guilford sites in Orwig and Foster 1998). In the northern regions where the low-impact sites were located, HWA was not present at any of the study sites in 1998, but was detected in 2005 surveys in the region (Preisser et al. 2008).

\section{Invertebrate sampling methods}

Our invertebrate sampling regimen was designed to parallel the methods used by Rohr et al. (2009) in their census of hemlock invertebrates. We used a variety of techniques to collect specimens from multiple forest strata that represent a broad range of primary guilds (Table 1). Sites were sampled 24 June-1 July 2008 and 20-28 September 2008 in order to incorporate seasonal variation in invertebrate communities. A $20-$ x $20-\mathrm{m}$ plot was established in the center of each site, chosen to represent the stand as a whole. Random selection and sampling along transects within the 20- x 20-m plots were used to

Table 1. Collection methods and number used to sample invertebrates during each sampling date in low-impact and high-impact hemlock forests in 2008. Samples were collected per site per date.

\begin{tabular}{llc} 
Collection method & Strata & Samples \\
\hline Pitfall trap & Ground & 6 \\
Leaf litter & Ground & 10 \\
Sweep net & Subcanopy & 6 \\
Beat sheet & Subcanopy & 5 \\
Lower branch clippings & Subcanopy & 5 \\
Upper branch clippings & Canopy & 5 \\
\hline
\end{tabular}


standardize methods among sites. Specimens collected using each sampling method (described below) were stored in ethyl alcohol and initially sorted into different morphospecies (except for Acari which were only sorted to order). Following the initial sorting process, we identified each morphospecies to family. The USDA Systemic Entomological Laboratory provided assistance with identifications. Reference samples are currently stored with the USDA Forest Service Northern Research Station in Hamden, CT, and will be permanently stored with the Yale-Peabody Museum.

Ground-zone sampling methods. 1) Six pitfall traps were deployed at each site along 2 transects, running parallel to the top and bottom edge of each $20-\mathrm{x}$ $20-\mathrm{m}$ plot on the first day of sampling. Traps were made of empty 0.4 -L tin cans with holes drilled in the top to prevent overflowing and filled with five cm of $60 \%$ ethanol. After three days, the traps were collected and the invertebrates recovered. 2) Ten leaf-litter samples were collected from randomly selected locations within the 20- x 20-m plot on the first day of sampling. For each sample, a $0.25-\mathrm{x}$ $0.25-\mathrm{m}$ frame was placed on the ground and all leaf litter and debris within the frame was collected and placed in a plastic bag. Upon return to the laboratory, the invertebrates were extracted from leaf-litter samples into ethyl alcohol over a 5-day period using a Berlese funnel.

Subcanopy zone sampling methods. 1) Six sweep-net samples of low-lying vegetation were collected from randomly chosen starting locations within the 20- x 20-m plot on the first day of sampling. All sweep-net samples were taken on a north-south axis and consisted of a 10-m transect with a sweep taken every $1 \mathrm{~m}$ ( 10 sweeps per sample, for a total of 60 sweeps per site). Captured invertebrates were transferred to a kill jar. 2) Beat-sheet samples were taken from five randomly selected understory trees/shrubs (defined as $>1 \mathrm{~m}$ in height but not reaching the uppermost layer of the canopy within the plot and surrounding forest) within the 20- x 20-m plot on the first day of sampling. A $1-x 1-m$ beat sheet was used to catch invertebrates dislodged in a 45-second sampling period. During the sampling period, one researcher vigorously shook the vegetation while another researcher used an aspirator to collect the dislodged invertebrates. Invertebrates that were too large to fit in the aspirator were collected by hand. Following the sampling period, all invertebrates were transferred to a kill jar. 3) One 0.5-m lower branch clipping was collected from 5 randomly selected trees/tall shrubs (defined as $>1 \mathrm{~m}$ height) within the 20- x 20-m plot on the first day of sampling. Each branch clipping was placed in a sealed plastic bag. Immediately upon return to the laboratory, all branch clippings were placed in a $-15{ }^{\circ} \mathrm{C}$ freezer for a minimum of one day. Following this period, each branch clipping was inspected and any invertebrates were manually removed.

Upper branch sampling methods. Using a pole pruner $2 \mathrm{~m}$ in length, a single 0.5-m branch clipping was taken from the highest reachable foliage $(3.5-4 \mathrm{~m}$ above ground level) on each of 5 randomly selected canopy trees within the 
20- x 20-m plot on the first day of sampling. Branches were held by the pole pruner upon being clipped and placed directly in a plastic bag and sealed. Immediately upon return to the lab, all branch clippings were placed in a $-15{ }^{\circ} \mathrm{C}$ freezer for a minimum of one day. Following this period, each branch clipping was inspected and invertebrates manually removed.

\section{Vegetation sampling methods}

All vegetation sampling and identification was performed during the fall, when personnel with vegetative taxonomic experience were able to assist. Canopy trees within the 20- x 20-m plots were identified to genus and species and the diameter at breast height recorded. Four 3.5- x 3.5-m subplots, 2 along each transect used to place pitfall traps, were sampled to identify the shrub stratum at each site. These subplots were sampled for vegetation cover and abundance using the Braun-Blanquet cover-abundance method (Wikum and Shanholtzer 1978). All shrubs $>1 \mathrm{~m}$ in height within the subplots were identified to genus and species. Six 1- x 1-m subplots, 3 along each transect used to place pitfall traps, were sampled to identify the herbaceous layer within each plot. All vegetation $<1 \mathrm{~m}$ in height inside the subplots was identified to genus and species.

\section{HWA and hemlock sampling methods}

We counted the number of hemlock trunks reaching breast height within the 20- x 20-m plot at each site. Each hemlock was classified as dead or alive. HWA densities were counted by randomly selecting 4 branchlets per tree (one in each cardinal direction) representing both the current year's and previous year's growth. HWA density was determined by counting the number of HWA sistens per cm of branchlet growth.

\section{Tree condition and other major herbivores}

We assessed tree health and canopy density using a rating system quantifying the percentage of needles remaining in the lowest, middle, and upper tree canopy; details of this rating system are discussed elsewhere (Preisser et al 2008). All high-impact sites had $<24 \%$ of hemlock needles remaining, almost exclusively on the upper portion of the trees. A second invasive herbivore, Fiorinia externa Ferris (Elongate Hemlock scale [EHS]) was present at all sites surveyed (MillerPierce et al. 2010, Preisser et al. 2008). EHS can cause premature needle loss when present in high densities, although tree mortality is rare (McClure 1980, Radville et al. 2011). One low-impact site with a relatively high EHS infestation had $50-74 \%$ of hemlock canopy remaining; all other low-impact sites had $>75 \%$ of hemlock canopy remaining.

\section{Statistical analyses}

Community composition was graphically compared among high- and lowimpact hemlock stands using non-metric multidimensional scaling (NMDS), an ordination approach well suited for use in ecological data where assumptions of normality are often violated (see McCune and Grace 2002 for discussion). 
Ordinations were generated using a Sorensen (Bray-Curtis) distance measure, and groups were statistically compared using a multi-response permutation procedure (MRPP) statistic. Both NMDS and MRPP were conducted using PCOrd v. $5.31\left(\mathrm{MjM}^{\mathrm{tm}}\right.$ Software). Species richness and abundance, pooled across sampling methods to compare the communities at the stand-level, were computed using EstimateS (Colwell 2009). Shannon-Weaver diversity indices were calculated using the equation $\mathrm{H}^{\prime}=\Sigma-\mathrm{p}_{\mathrm{i}} \ln \left(\mathrm{p}_{\mathrm{i}}\right)$. Indicator species analysis was conducted using PCOrd v. 5.31, with 4999 randomizations (MjM ${ }^{\mathrm{tm}}$ Software). For comparing differences in hemlock mortality, number of plant species, and HWA density by stand type, ANOVA was used in the statistical software program JMP v. 7.0 (SAS Institute, Inc. 2007).

\section{Results}

Low-impact and high-impact sites varied significantly in vegetation structure (Fig 1). Although the number of mature (DBH $>9 \mathrm{~cm}$ ) deciduous hardwood tree species found did not differ between high-impact and low-impact habitats (mean \# of trees \pm SE: $8.25 \pm 2.92$ and $12.5 \pm 1.19$, respectively; $F_{1,7}=1.18, P=0.23$ ), high-impact sites had fewer surviving hemlocks than low-impact sites $\left(1.5 \pm 0.65\right.$ trees and $20.5 \pm 2.72$, respectively; $F_{1,7}=46.09$,

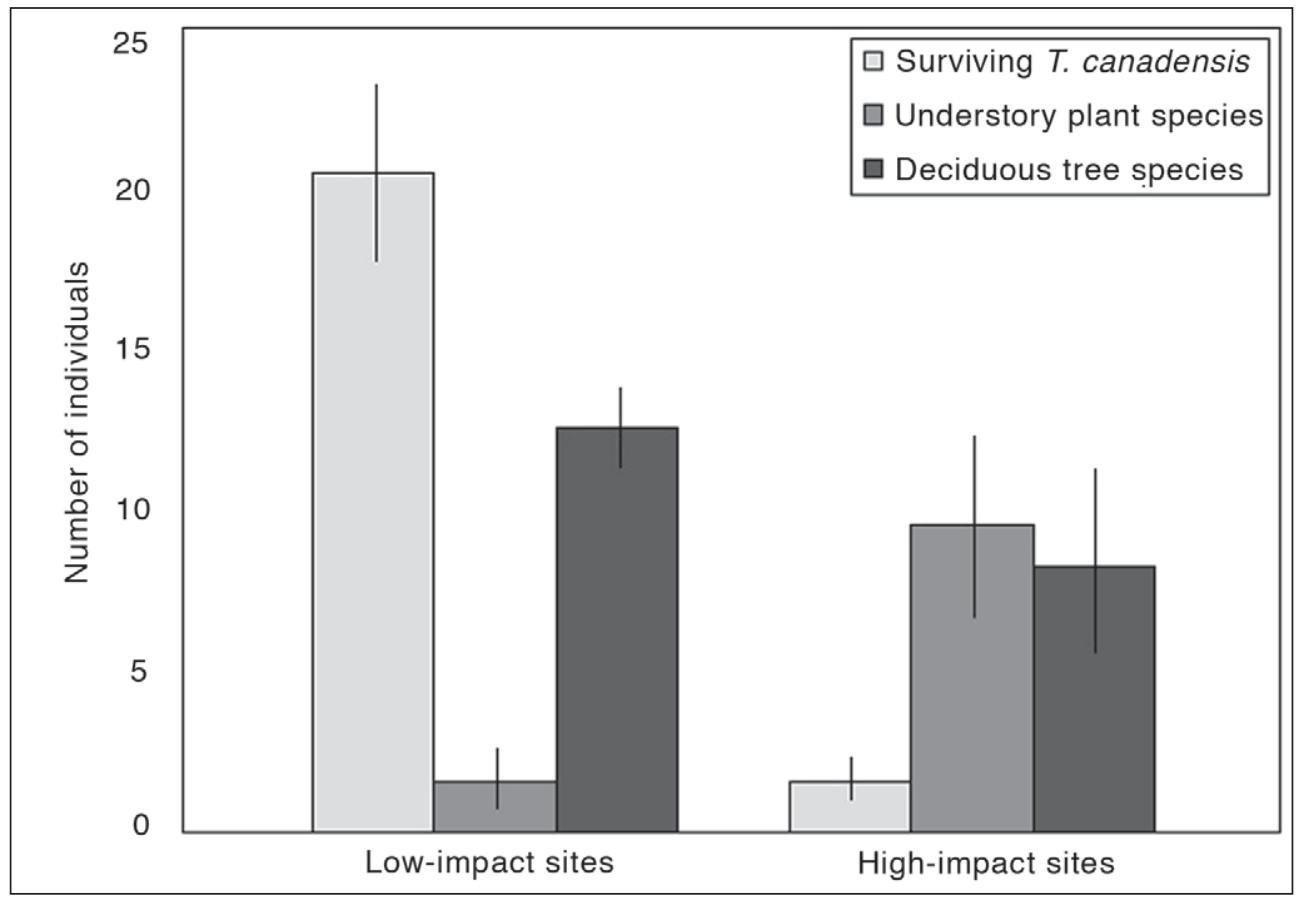

Figure 1. Vegetation analysis comparing low- and high-impact forest sites. Sites varied significantly in both the mean number of living hemlocks found $(P<0.001)$ and the mean number of understory species present $(P=0.038)$. Differences in the number of deciduous hardwood species were not significant $(P=0.227)$. Bars represent plot means \pm standard error. 
$P<0.001)$. In contrast, high-impact sites had a greater richness of herbaceous plants than low-impact sites (mean \# species \pm SE: $9.5 \pm 2.90$ and $1.5 \pm 0.87$, respectively; $\left.F_{1,7}=6.98, P=0.038\right)$. High- and low-impact sites did not, however, differ in terms of shrub richness (mean \# species \pm SE: $1.3 \pm 0.75$ and $1.0 \pm 0.41$, respectively; $F_{1,6}=0.08, P=0.78$ ). The most common species at high-impact sites in the herbaceous and shrub layer were Betula lenta L. (Black Birch; 18\% of individuals), Acer rubrum L. (Red Maple; 17\%), Maianthemum canadense Desf. (Canada Mayflower; 8\%), Hamamelis virginiana L. (Witch-hazel; 7\%), Quercus rubra L. (Red Oak; 7\%) and Quercus prinus L. (Chestnut Oak; 7\%). A single hemlock seedling was found in the understory $(<1 \mathrm{~m})$ at one high-impact site. Vegetation in the herbaceous and shrub layer at low-impact sites was dominated by Eastern Hemlock (44\% of individuals), Red Maple (13\%), and Quercus alba L. (White Oak; 13\%). Black Birch was not found at the low-impact sites. In addition to richness and abundance, we compared communities using the Shannon-Weaver diversity index. This index uses species richness and evenness to calculate a value typically ranging from 1 to 5. Our results indicate that the high-impact forests are more diverse and even in vegetative communities than the low-impact forests $(2.44 \pm 0.16$ and $1.45 \pm 0.14$, respectively; $F_{1,6}=21.3, P=0.004$; Table 2 ). HWA densities differed between site type, with high-impact sites averaging $11.6 \mathrm{HWA} / \mathrm{cm}$ new growth versus $0.22 \mathrm{HWA} / \mathrm{cm}$ for low-impact sites $\left(F_{1,6}=32.5, P<0.002\right)$.

We collected 8787 specimens of 623 morphospecies belonging to 5 different arthropod classes: Arachnida, Malacostraca, Diplopoda, Chilopoda, and Hexapoda. All individuals in the order Acari were grouped together. Acari were the most abundant order in the healthy hemlock stands, comprising almost half of the arthropod samples collected (Fig. 2). The arthropod community in the high-impact sites consisted primarily of Acari and Collembola, followed closely by Coleoptera. The most abundant feeding guild in all of the sample sites and seasons were predators, followed by detritivores and

Table 2. Mean ( \pm standard error) values of observed abundance, observed species richness, and Shannon-Weaver diversity index $\left(\mathrm{H}^{\prime}\right)$ for invertebrate and vegetation communities. Seasonal differences are reported individually for invertebrate communities. Sampling methods and vegetative zones were combined to represent data at the stand level.

\begin{tabular}{llcc} 
Community/site & Abundance & Richness & $\mathrm{H}^{\prime}$ \\
\hline Invertebrate & & & \\
High impact (summer) & $504.8 \pm 75.3$ & $152.7 \pm 3.9$ & $3.67 \pm 0.15$ \\
High impact (fall) & $397.1 \pm 147.3$ & $73.7 \pm 13.4$ & $2.97 \pm 0.28$ \\
Low impact (summer) & $729.5 \pm 239.4$ & $139.0 \pm 14.0$ & $2.84 \pm 0.54$ \\
Low impact (fall) & $495.3 \pm 158.3$ & $80.7 \pm 8.1$ & $2.77 \pm 0.30$ \\
Composite high impact & $450.9 \pm 79.2$ & $113.2 \pm 16.3$ & $3.65 \pm 0.17$ \\
Composite low impact & $612.4 \pm 140.0$ & $109.9 \pm 13.3$ & $2.89 \pm 0.30$ \\
Vegetation & & & \\
High impact & $37.0 \pm 3.7$ & $14.3 \pm 2.6$ & $2.44 \pm 0.16$ \\
Low impact & $27.0 \pm 3.6$ & $7.8 \pm 0.8$ & $1.45 \pm 0.14$ \\
\hline
\end{tabular}


phytophages (Fig. 3). Parasites and mycophages rounded out the 5 most commonly collected feeding guilds.

Invertebrate community composition indices revealed the two stand types varied in both species richness and abundance (Table 2). Throughout this section, "species" refers to morphospecies within a given family; although we attempted to identify organisms to genus and species, a lack of taxonomic expertise (also cited as a problem in Rohr et al. 2009) meant that family was the lowest taxonomic level we could consistently identify with accuracy. Species abundance and richness were higher during the summer collection times than during the fall. Because we were most interested in comparing overall community structure rather than seasonal differences, we pooled the collection methods and sampling dates in our analyses except in Table 2, where both seasonal and pooled data are reported. High-impact sites had a lower arthropod abundance than low-impact sites $(451 \pm 79.2$ and $612 \pm 140.0$ individuals/location, respectively; Table 2), but were essentially equivalent in species richness $(113 \pm 16.3$ and $110 \pm 13.3$ morphospecies, respectively; Table 2). The high variability displayed in the standard error value for the arthropod abundance in the low-impact sites is attributed to over 800 mites that were collected in pitfall traps at one low-impact location. The Shannon-Weaver diversity index indicates that the high-impact forests are slightly more diverse in invertebrate communities than the low-impact forests (3.65 \pm 0.17 and $2.89 \pm 0.30$, respectively; Table 2$)$.

Indicator species analysis revealed 21 species that were statistically associated with a given forest type; 14 of these were high-impact indicators, while 7

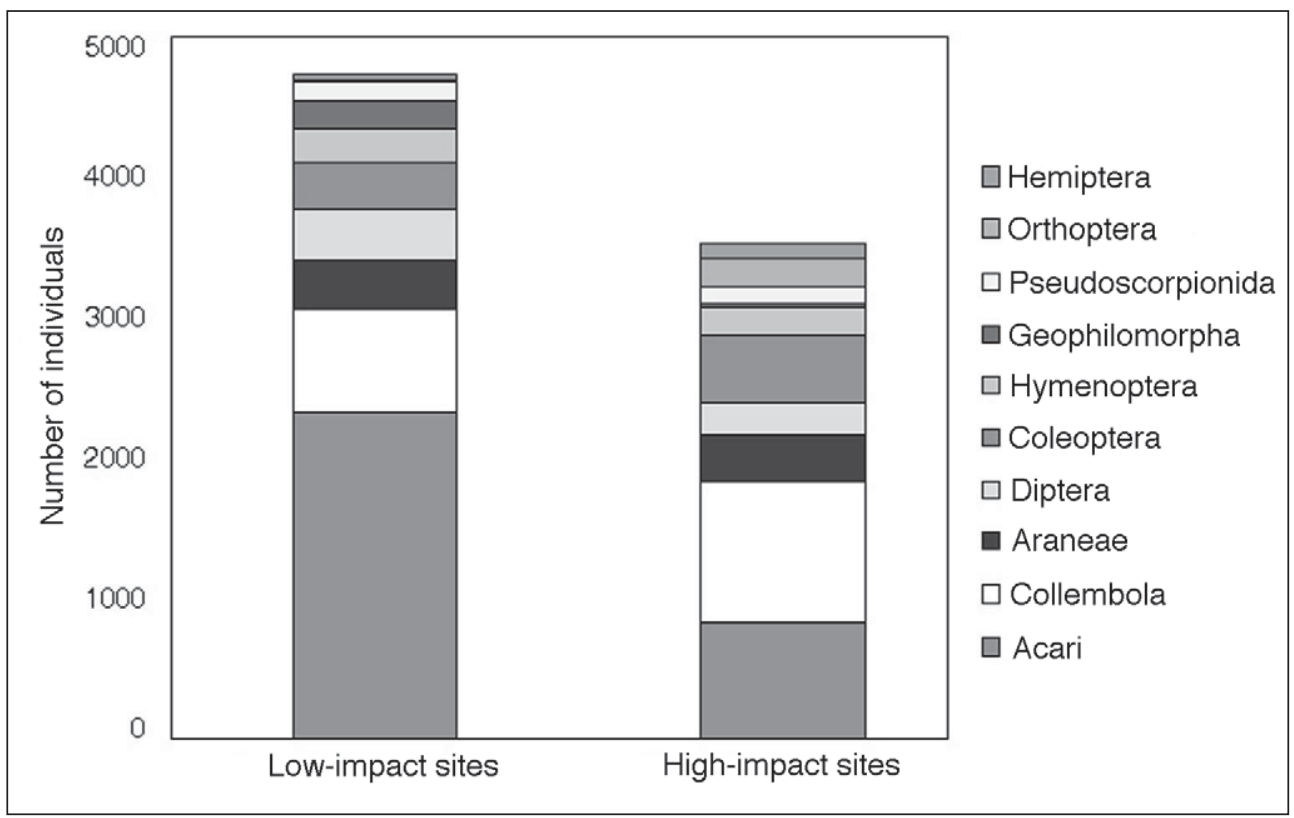

Figure 2. Total abundance of the most common arthropods in low- and high-impact hemlock forests. The figure displays greater than $96 \%$ and $91 \%$, of the arthropods in the low-impact and high-impact stands, respectively. 
were low-impact indicators (Table 3). All of the feeding guilds collected were represented among the indicator species. The most abundant indicator species was a Geophilomorpha sp. centipede, all 223 individuals of which were collected in low-impact stands. The rarest indicator species were all found in high-impact sites and include species from the Phalangidae (5), Nabidae (5), and Anthicidae (7) families (Table 3).

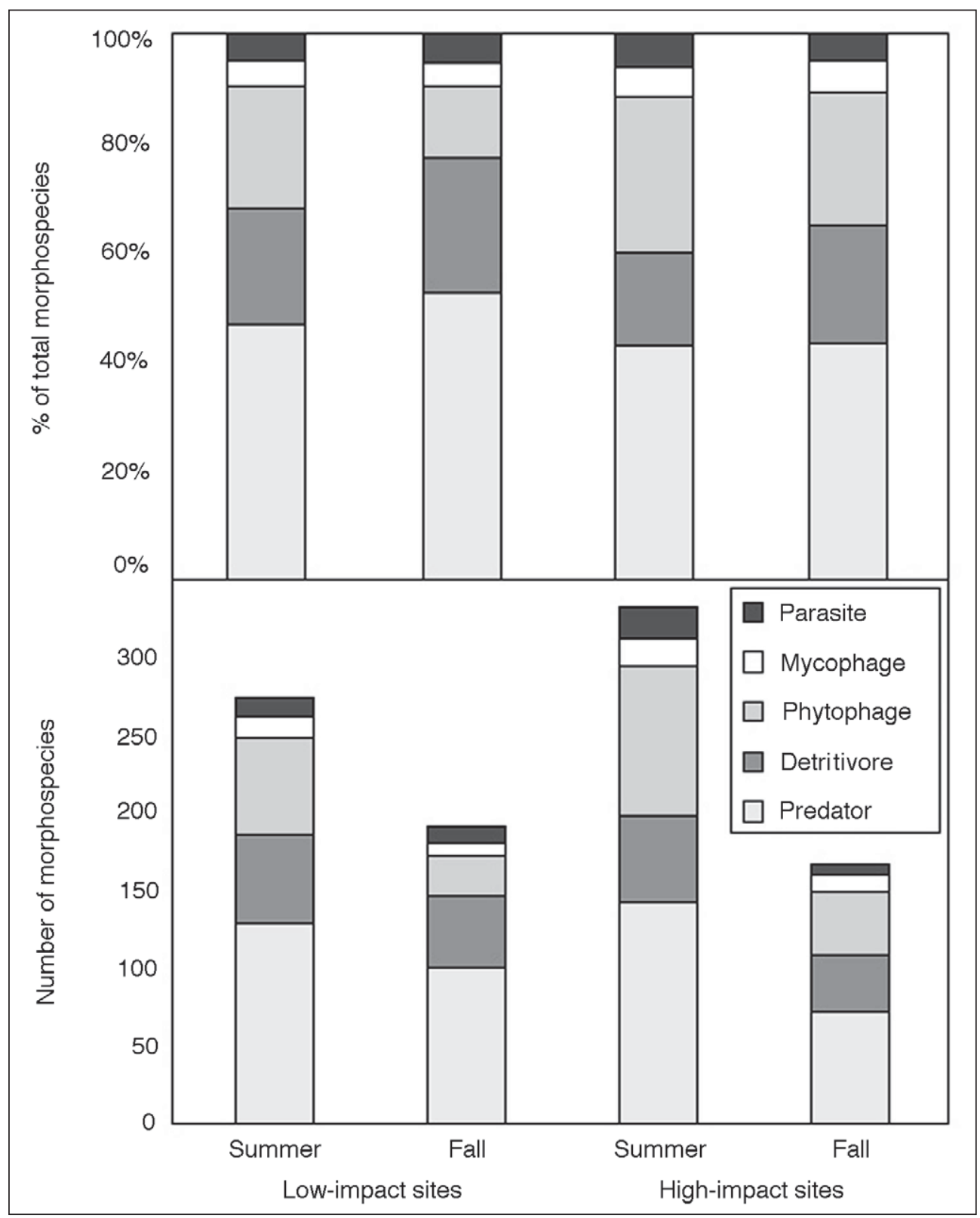

Figure 3. Proportional abundance of morphospecies in each of the five most common feeding guilds (top panel) and their absolute number (bottom panel) in low- and highimpact hemlock stands. 


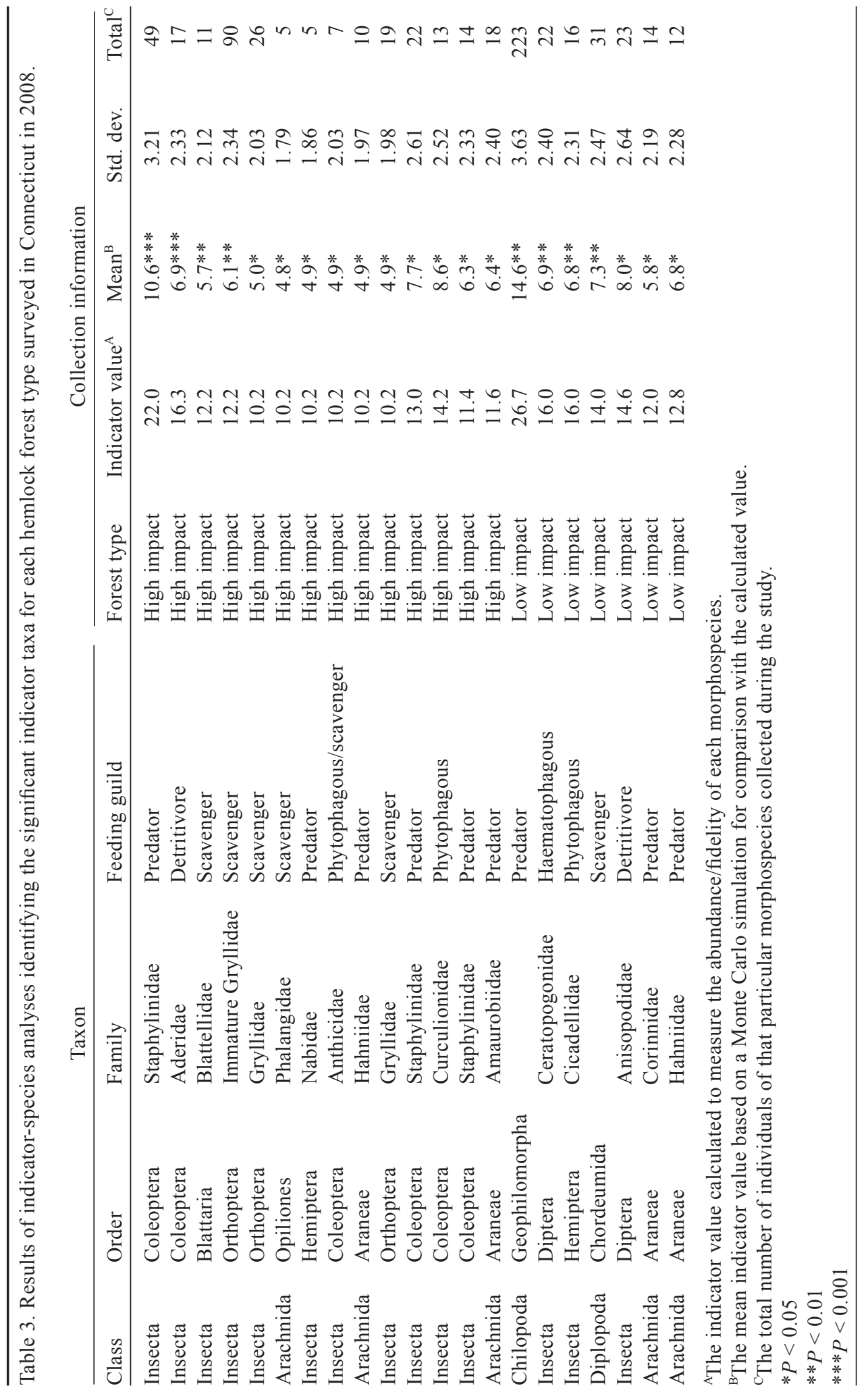


Examining community composition based on sampling method, the most distinct differences between low-impact and high-impact sites occurred while sampling in the subcanopy and upper branch zones (using branch clips, beat sheets, and sweep-net methods; Fig. 4). Because our analyses revealed no significant differences between these collection methods, they were pooled when comparing low-impact and high-impact sites for future analyses and are referred to as the canopy community (Table 4). A post-hoc analysis of the different strata in the stands indicates the high-impact and low-impact locations differed in community composition at the canopy and subcanopy levels (MRPP $P=0.016$; Table 4, Fig. 4). In contrast, arthropod community composition at the ground level did not differ between the two types of sites (pitfall and leaf-litter methods; $P=0.278$ and $P=0.422$, respectively).

\section{Discussion}

The spread of HWA across New England has provided the opportunity to examine the biodiversity impacts of HWA invasion in Connecticut, where the

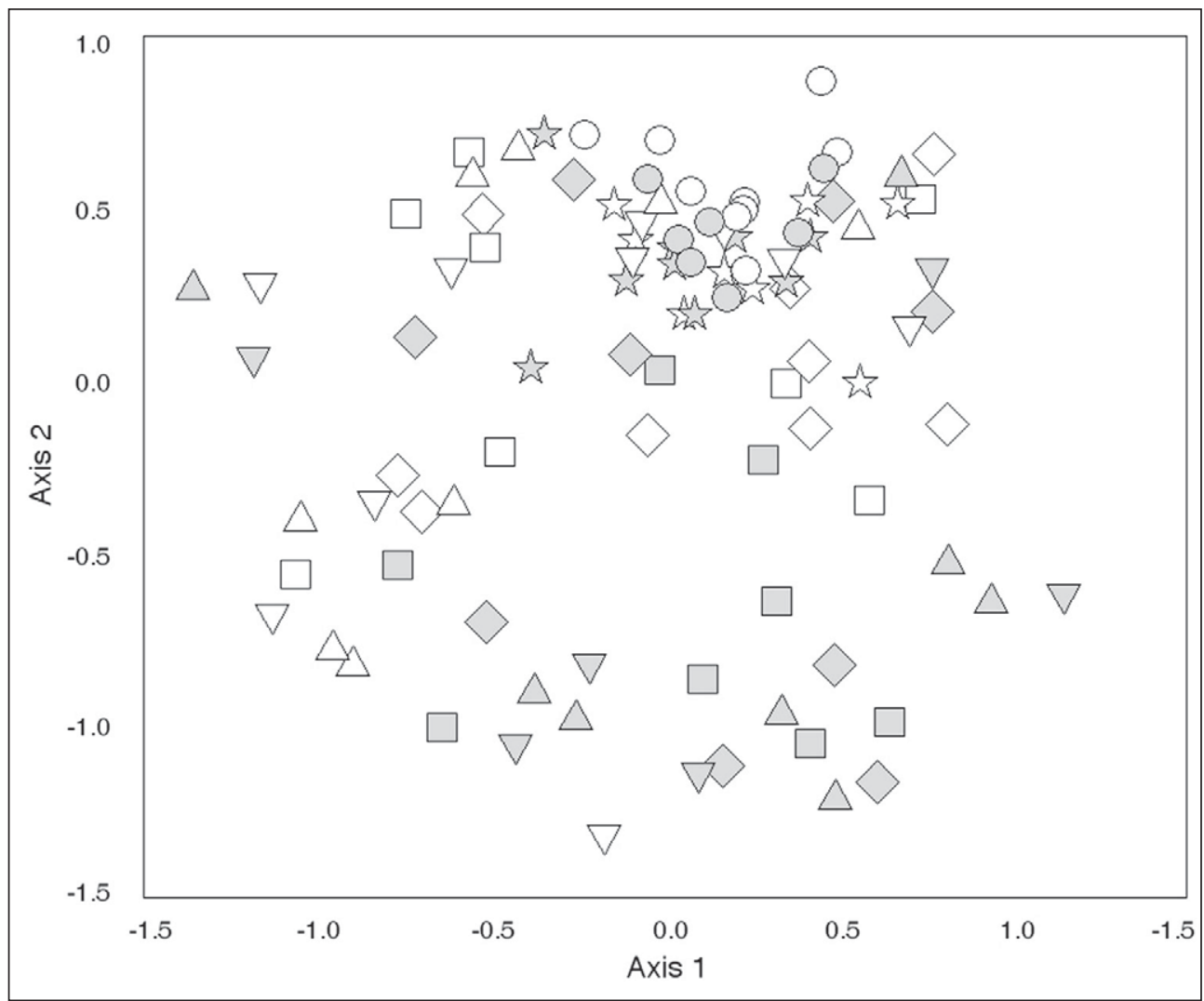

Figure 4. Non-metric multidimensional scaling (NMDS) ordination of communities defined by stand type and collection method. Ordination is based on Sorenson (Bray-Curtis) distance measures. Open symbols indicate low-impact stands and filled symbols indicate high-impact stands. Triangle $=$ lower branch clip, inverted triangle $=$ upper branch clip, square $=$ beat sheet, diamond $=$ sweep net, star $=$ leaf litter, and circle $=$ pitfall trap . 
impact of the adelgid has varied across space and through time. When we began our study in 2008, HWA had only recently reached several of our low-impact sites (Preisser et al. 2008) and had not yet caused significant foliage loss. In addition to differences in vegetation composition and diversity in high- and low-impact stands, we also documented hemlock regeneration at the low-impact sites, while the species regenerating in the forest gaps at high-impact sites consisted mostly of deciduous hardwoods and shrubs. This finding supports previous research that found an inverse relationship between HWA density and hemlock recruitment (Orwig and Foster 1998, Preisser et al. 2011) and is consistent with other studies documenting the replacement of Eastern Hemlock by multiple hardwood species (Mahan et al. 2004, Spaulding and Rieske 2010). Other studies have also shown Black Birch to be one of the first tree species to establish and dominate the understory immediately after hemlock mortality (Orwig and Foster 1998, Rohr et al. 2009). Black Birch was the most abundant species in the herb and shrub layer in the high-impact sites in our study.

Past studies have shown that arthropod communities are highly sensitive to changes in vegetative structure, host condition, genotype, and ontogeny (Dungey et al. 2000, Schaffers et al. 2008, Trotter et al. 2008, Wimp et al. 2005). Invasive herbivores can induce changes in native arthropod communities by increasing competition on a shared host, thus reducing vegetative

Table 4. Statistical comparisons of arthropod community composition among canopy strata and between high- and low-impact stands. Community composition did not differ statistically among upper canopy, lower canopy, sweep-net, and beat-sheet collection methods, and were pooled to create the "canopy" stratum. Groups: 1 = canopy in high-impact sites, 2 = leaf litter in high-impact sites, 3 = pitfall traps in high-impact sites, $4=$ canopy in low-impact sites, $5=1$ leaf litter in low-impact sites, and $6=$ pitfall traps in low-impact sites. Bold values are significant at $P<0.05$. MRPP $=$ multi-response permutation procedure. A is the chance-corrected withingroup agreement $(0=$ no within-group homogeneity, $1=$ perfect within-group homogeneity). $\mathrm{T}$ is the calculated test statistic.

\begin{tabular}{lccr} 
& \multicolumn{3}{c}{ MRPP } \\
\cline { 2 - 4 } Group comparisons & $\mathrm{T}$ & $\mathrm{A}$ & \multicolumn{1}{c}{$P$} \\
\hline 1 vs. 2 & -6.70 & 0.024 & $<\mathbf{0 . 0 0 1}$ \\
1 vs. 3 & -8.01 & 0.027 & $<\mathbf{0 . 0 0 1}$ \\
1 vs. 4 & -2.95 & 0.007 & $\mathbf{0 . 0 1 6}$ \\
1 vs. 5 & -5.73 & 0.024 & $<\mathbf{0 . 0 0 1}$ \\
1 vs. 6 & -9.30 & 0.034 & $\mathbf{0 . 0 0 1}$ \\
2 vs. 3 & -2.69 & 0.028 & $\mathbf{0 . 0 1 0}$ \\
2 vs. 4 & -5.23 & 0.022 & $\mathbf{0 . 0 0 1}$ \\
2 vs. 5 & -2.43 & 0.039 & 0.422 \\
2 vs. 6 & -0.04 & 0.000 & $\mathbf{0 . 0 2 6}$ \\
3 vs. 4 & -7.32 & 0.029 & $<\mathbf{0 . 0 0 1}$ \\
3 vs. 5 & -0.44 & 0.007 & $\mathbf{0 . 0 0 1}$ \\
3 vs. 6 & -4.28 & 0.045 & 0.278 \\
4 vs. 5 & -5.09 & 0.024 & $<\mathbf{0 . 0 0 1}$ \\
4 vs. 6 & -7.70 & 0.033 & $\mathbf{0 . 0 0 1}$ \\
5 vs. 6 & -2.29 & 0.038 & $\mathbf{0 . 0 3 1}$
\end{tabular}


diversity, displacing native organisms, and altering ecosystems (see Kenis et al. 2009 for review). What is less understood is how these communities will change as a result of an introduced forest-altering herbivore. We documented rapid changes in the understory vegetative communities and a corresponding shift in the subcanopy- and canopy-level invertebrate communities within these ecosystems. The fact that ground-level arthropod diversity did not differ between high- and low-impact sites suggests that species in this habitat are either less reliant on specific plant species or that they exhibit a delayed response to changes in vegetation structure. This result is intriguing because it suggests that alterations in leaf-litter changes were less important to groundfeeding arthropods than foliar changes were to herbivores. Spaulding and Rieske (2010) found that once HWA has reached high densities in a hemlock stand, it can take up to 20 years for vegetation structure to shift to a hardwood-dominated community. McClure (1991) documented HWA infestations in southern CT starting in 1986 (East Hampton, East Haddam, and Essex) and 1987 (Guilford, CT). Although the exact dates of initial HWA infestation in our study plots are unknown, we documented changes in vegetative structure between areas at the onset of HWA invasion and in heavily affected stands where hardwood regeneration is already occurring (Orwig and Foster 1998). These data provide a trajectory of community change and highlight the importance of monitoring currently and newly infested stands to provide additional data on the rates of change induced by adelgid infestation.

The most abundant organisms collected in the ground-level sampling methods were Acari. Although we were unable to identify Acari past order, Rohr et al. (2009) found several Acari species were indicators of Eastern Hemlock forests in the Appalachian Mountains of Virginia. Acari were among the 5 most abundant orders of invertebrates collected in both the low- and high-impact sites, and were the most abundant organisms in low-impact sites. Although it is possible (and perhaps likely) that increased precision in the taxonomic classification of Acari could reveal community-level changes, the resources necessary to support this work were not available at the time of this study, though the material remains available for future analyses.

In addition to providing data on the impact of the adelgid in the northern range of HWA, this data allows for a comparison of the impacts of the adelgid across its entire invaded range. Rohr et al. (2009) provides a detailed account of indicator taxa identified in hemlock forests in Shenandoah National Park (SNP) in Virginia. The class Chilopoda was represented by 5 morphospecies belonging to the order Lithobiomorpha among our collections. One of these morphospecies belonged to the family Lithiobiidae, another indicator taxa of hemlock forests in SNP (Rohr et al. 2009); although relatively rare, this morphospecies was collected exclusively in our low-impact sites. We collected five morphospecies belonging to the family Mycetophilidae (Diptera) in both high- and low-impact sites, none of which appeared as indicator species among our collections. This result contrasts with the fact that members of the Mycetophilid genus Tetragoneura are indicators 
of hardwood forests while the Mycetophilid genus Mycomya is an indicator of hemlock forests in SNP (Rohr et al. 2009). Other hemlock indicator species in SNP included Odiellus pictus (Opiliones: Phalangiidae) and Parajulidae sp. (Diplopoda: Julida) (Rohr et al. 2009). While not indicators in our study, we collected 2 Opiliones morphospecies in the genus Phalangium (Phalangiidae), and 2 morphospecies belonging to the order Julida (Diplopoda), one of which was present at both kinds of sites and one of which was present only at low-impact sites. This finding suggests that some of the similar indicator species may have occurred in both studies, and that further evaluation of the potential ecological roles and monitoring uses of indicator species may improve our landscape-scale understanding of the impact of HWA.

Low-impact indicator taxa identified in our results included 2 spiders: one member of the ground-running family Corinnidae and one member of the sheetweb-building family Hahniidae (Table 3). Predatory indicator species may indirectly reflect changes in the herbivore, detritivore, and fungivore communities which they consume, indicating that their prey species are less abundant or absent at high-impact sites (Hartman 1977). Interestingly, another morphospecies in the order Hahniidae was an indicator of high-impact forests (Table 3). Rohr et al (2009) identified Opiliones from the genus Leiobunum as indicators of hardwood forests in SNP. In our study, we collected several morphospecies belonging to this genus, one of which was also identified as an indicator of highimpact sites. Biting midges (Diptera: Ceratopogonidae; Table 3) provide another indicator of low-impact forests. Midges breed in wet grounds, and the understory of hemlock forests are much cooler and damper than the gaps created after HWA invasion and resulting hemlock mortality.

Our study has shown that the presence of HWA and ensuing loss of Eastern Hemlock has led to rapid shifts in the vegetation and arthropod community composition of New England hemlock forests. As hemlock forests are replaced by deciduous hardwoods across New England (but see Ingwell and Preisser 2011), our research suggests that the result will be a more diverse suite of understory vegetation that includes species such as Black Birch, Red Maple, Canada Mayflower, Witch-hazel, Red Oak, and Chestnut Oak. The invertebrate community characteristics of intact Eastern Hemlock forests will also shift in favor of communities dominated by the orders Orthoptera and Coleoptera (class Insecta) and Collembolans (class Entognatha). The lack of a strong effect of hemlock loss on overall invertebrate diversity belies the fact that the HWA-mediated removal of hemlocks from eastern forests threatens specific elements of insect diversity that are unique to hemlock. Ultimately, our work demonstrates that the herbivoremediated removal of a foundational tree species has the potential to substantially alter forest communities throughout New England.

\section{Acknowledgments}

This research would not have been possible without the help of J. Backer, D. Cox, K. Steinmann, J. Turner, and J. VanSant. S. Alm, R. Casagrande, C. Hart, and A. Weed 
assisted with identifications, as did the following taxonomists at the SEL USDA laboratory: D. Creel, D. Gaimari, W. Grogan, T. Henry, R. Kula, D. Miller, and A. Norrbom. Comments by the editor and two anonymous reviewers improved the clarity of the manuscript. Funding for this work was provided by a Sigma Xi Grant-in-Aid-of-Research and a URI Graduate Research Grant to LI. Additional funding was provided by an AES Hatch grant and NSF DEB\#0715504 to EP.

\section{Literature Cited}

Colwell, R.K. 2009. EstimateS: Statistical estimation of species richness and shared species from samples. Available online at http://purl.oclc.org/estimates.

Cowles, H.C. 1899. The Ecological Relations of the Vegetation on the Sand Dunes of Lake Michigan. The University of Chicago Press, Chicago, IL.

DeGraaf, R.M., M. Yamasaki, W.B. Leak, and J.W. Lanier. 1992. New England Wildlife: Management and forested habitats. USDA Forest Service Research Bulletin General Technical Report NE-144. Durham, NH.

Dilling, C., P. Lambdin, J. Grant, and L. Buck. 2007. Insect guild structure associate with Eastern Hemlock in the southern Appalachians. Environmental Entomology 36:1408-1414.

Dungey, H.S., B.M. Potts, T. G. Whitham, and H.F. Li. 2000. Plant genetics affects arthropod community richness and composition: Evidence from a synthetic eucalypt hybrid population. Evolution 54:1938-1946.

Ellison, A., M. Bank, B. Clinton, E. Colburn, K. Elliott, C. Ford, D. Foster, B. Kloeppel, J. Knoepp, G. Lovett, J. Mohan, D. Orwig, N. Rodenhouse, W. Sobczak, K. Stinson, J. Stone, C. Swan, J. Thompson, B. Von Holle, and J. Webster. 2005a. Loss of foundation species: Consequences for the structure and dynamics of forested ecosystems. Frontiers in Ecology and the Environment 3:479-486.

Ellison, A., J. Chen, D. Diaz, C. Krammerer-Bernham, and M. Lau. 2005b. Changes in ant community structure and composition associated with hemlock decline in New England. Pp. 280-289, In Brad Onken and Richard Reardon (Compilers). 3rd Symposium on Hemlock Woolly Adelgid in the Eastern United States. USDA Forest Service, Morgantown, WV.

Falcone, J.F., and L.E. DeWald. 2010. Comparisons of arthropod and avian assemblages in insecticide-treated and untreated Eastern Hemlock (Tsuga canadensis (L.) Carr) stands in Great Smoky Mountains National Park, USA. Forest Ecology and Management 260:856-863.

Hartman, H. 1977. Arthropod population composition as influences by individual hemlock trees interspersed in a hardwood stand. Forest Science 23:469-473.

Havill, N., M. Montgomery, G. Yu, S. Shiyake, and A. Caccone. 2006. Mitochondrial DNA from Hemlock Woolly Adelgid (Hemiptera: Adelgidae) suggests cryptic speciation and pinpoints the source of the introduction to eastern North America. Annals of the Entomological Society of America 99:195-203.

Ingwell, L.L., and E.L. Preisser. 2011. Using citizen science programs to identify host resistance in pest-invaded forests. Conservation Biology 25:182-188.

Kenis, M., M.-A. Auger-Rozenberg, A. Roques, L. Timms, C. Péré, M. Cock, J. Settele, S. Augustin, and C. Lopez-Vaamonde. 2009. Ecological effects of invasive alien insects. Biological Invasions 11:21-45.

Kizlinski, M., D. Orwig, R. Cobb, and D. Foster. 2002. Direct and indirect ecosystem consequences of an invasive pest on forests dominated by Eastern Hemlock. Journal of Biogeography 29:1489-1504. 
Mahan, C., K.L. Sullivan, B. Black, K.C. Kim, and R.H. Yahner. 2004. Overstory tree composition of Eastern Hemlock stands threatened by the Hemlock Woolly Adelgid at Delaware Water Gap National Recreation Area. Castanea 69:30-37.

McClure, M. 1980. Competition between exotic species: Scale insects on hemlock. Ecology 61:1391-1401.

McClure, M. 1987. Biology and control of Hemlock Woolly Adelgid. Bulletin of the Connecticut Agricultural Experiment Station 851. New Haven, CT.

McClure, M. 1991. Density-dependent feedback and population cycles in Adelges tsugae (Homoptera: Adelgidae) on Tsuga canadensis. Environmental Entomology 20:258-264.

McCune, B., and J.B. Grace. 2002. Analysis of Ecological Communities. MjM Software Design, Gleneden Beach, OR.

Miller-Pierce, M.R., D.A. Orwig, and E. Preisser. 2010. Effects of Hemlock Woolly Adelgid and Elongate Hemlock Scale on Eastern Hemlock growth and foliar chemistry. Environmental Entomology 39:513-519.

Orwig, D., and D. Foster. 1998. Forest response to the introduced Hemlock Woolly Adelgid in southern New England, USA. Journal of the Torrey Botanical Society 125:60-73.

Orwig, D., D. Foster, and D. Mausel. 2002. Landscape patterns of hemlock decline in New England due to the introduced Hemlock Woolly Adelgid. Journal of Biogeography 29:1475-1488.

Paradis, A., J. Elkinton, K. Hayhoe, and J. Buonaccorsi. 2008. Role of winter temperature and climate change on the survival and future range expansion of the Hemlock Woolly Adelgid (Adelges tsugae) in eastern North America. Mitigation and Adaptation Strategies for Global Change 13:541-554.

Preisser, E., A. Lodge, D. Orwig, and J. Elkinton. 2008. Range expansion and population dynamics of co-occurring invasive herbivores. Biological Invasions 10:201-213.

Preisser, E.L., M.R. Miller-Pierce, J. Vansant, and D.A. Orwig. 2011. Eastern Hemlock (Tsuga canadensis) regeneration in the presence of Hemlock Woolly Adelgid (Adelges tsugae) and Elongate Hemlock Scale (Fiorinia externa). Canadian Journal of Forest Research 41:2433-2439.

Radville, L., A. Chaves, and E.L. Preisser. 2011. Variation in plant defense against invasive herbivores: Evidence for a hypersensitive response in Eastern Hemlocks (Tsuga canadensis). Journal of Chemical Ecology 37:592-597.

Rohr, J.R., C. Mahan, and K.C. Kim. 2009. Response of arthropod biodiversity to foundation species declines: The case of the Eastern Hemlock. Forest Ecology and Management:1503-1510.

SAS Institute, Inc. 2007. JMP. Cary, NC.

Schaffers, A.P., I.P. Raemakers, K.V. Sýkora, and C.J.F. ter Braak. 2008. Arthropod assemblages are best predicted by plant species composition. Ecology 89:782-794.

Snyder, C.D., J.A. Young, D.P. Lemarie, and D.R. Smith. 2002. Influence of Eastern Hemlock (Tsuga canadensis) forests on aquatic invertebrate assemblages in headwater streams. Canadian Journal of Fisheries and Aquatic Sciences 59:262-275.

Spaulding, H.L., and L.K. Rieske. 2010. The aftermath of an invasion: Structure and composition of central Appalachian hemlock forests following establishment of the Hemlock Woolly Adelgid, Adelges tsugae. Biological Invasions 12:3135-3143. 
Stadler, B., T. Müller, D. Orwig, and R. Cobb. 2005. Hemlock Woolly Adelgid in New England forests: Canopy impacts transforming ecosystem processes and landscapes. Ecosystems 8:233-247.

Tingley, M.W., D.A. Orwig, and R. Field. 2002. Avian response to removal of a forest dominant: Consequences of Hemlock Woolly Adelgid infestations. Journal of Biogeography 29:1505-1516.

Trotter, T.R.I., N.S. Cobb, and T.G. Whitham. 2008. Arthropod community diversity and trophic structure: A comparison between extremes of plant stress. Ecological Entomology 33:1-11.

US Department of Agriculture (USDA). 2010. Hemlock Wooly Adelgid map. US Forest Service GIS Group, Durham, NH.

Wikum, D.A., and G.F. Shanholtzer. 1978. Application of the Braun-blanquet coverabundance scale for vegetation analysis in land-development studies. Environmental Management 2:323-329.

Wimp, G.M., G. D. Martinsen, K.D. Floate, R.K. Bangert, and T.G. Whitham. 2005. Plant genetic determinants of arthropod community structure and diversity. Evolution 59:61-69.

Young, J.A., D.R. Smith, C.D. Snyder, and D.P. Lemarie. 2002. A terrain-based pairedsite sampling design to assess biodiversity losses from Eastern Hemlock decline. Environmental Monitoring and Assessment 78:327-328. 